\title{
Long-Term Quality of Life Improvement in Subjects with Healed Erosive Esophagitis: Treatment with Lansoprazole
}

\author{
Thomas O. Kovacs $\cdot$ James W. Freston $\cdot$ \\ Marian M. Haber · Stuart Atkinson • \\ Barbara Hunt · David A. Peura
}

Received: 12 January 2009/Accepted: 22 May 2009/Published online: 7 July 2009

(c) The Author(s) 2009. This article is published with open access at Springerlink.com

\begin{abstract}
Background Gastroesophageal reflux disease (GERD) is a chronic symptomatic condition and may be associated with erosive esophagitis (EE). Considerable data on the long-term maintenance of healing of EE are available, but data on long-term GERD symptom prevention and patient quality of life (QOL) are limited.

Aims To investigate QOL in subjects with healed EE who received 12 months of double-blind maintenance treatment with lansoprazole or ranitidine, followed by long-term open-label lansoprazole therapy to prevent recurrence of EE.

Methods Subjects with healed EE received 12 months of double-blind maintenance treatment with lansoprazole $15 \mathrm{mg}$ once daily or ranitidine $150 \mathrm{mg}$ twice daily,
\end{abstract}

T. O. Kovacs $(\square)$

CURE Digestive Diseases Research Center, VA Greater Los

Angeles Healthcare System, Los Angeles, CA 90073, USA

e-mail: TKovacs@mednet.ucla.edu

J. W. Freston

University of Connecticut Health Center, Farmington, CT, USA

M. M. Haber

Department of Pathology, Drexel University College

of Medicine, Philadelphia, PA, USA

S. Atkinson

Clinical Science Department, Takeda Global Research

\& Development Center, Inc., Deerfield, IL, USA

B. Hunt

Statistics Department, Takeda Global Research \& Development Center, Inc., Deerfield, IL, USA

D. A. Peura

Division of Gastroenterology and Hepatology, University

of Virginia Health System, Charlottesville, VA, USA followed by dose-titrated, open-label lansoprazole therapy for up to 82 months.

Results During double-blind treatment $(n=206)$, lansoprazole-treated patients showed significantly $(P \leq$ $0.05)$ greater improvements than ranitidine-treated patients in the frequency, severity, and 'bothersomeness' of heartburn, the symptom index, problems of activity limitation, eating and drinking problems, symptom problems, health distress, and social functioning. During dose-titrated, openlabel treatment $(n=195)$, all disease-specific QOL scales except sleep improved significantly $(P<0.001)$ from openlabel baseline at each time-point.

Conclusions Maintenance treatment with lansoprazole for 12 months in healed EE subjects produced significantly greater improvements in QOL indicators than ranitidine. These improvements were sustained during dose-titrated, open-label lansoprazole treatment.

Keywords Quality of life - Lansoprazole ·

Erosive esophagitis - Gastroesophageal reflux disease .

Long-term maintenance therapy

\section{Introduction}

Gastroesophageal reflux disease (GERD) is a chronic symptomatic condition defined as symptoms or mucosal damage produced by the abnormal reflux of gastric contents into the esophagus. Long-term treatment to maintain healing and symptom relief is often necessary to prevent erosive esophagitis (EE) and other complications [1]. Recent treatment guidelines for GERD support symptomdriven therapy [2], although endoscopic studies suggest that, in most patients, EE will relapse when proton pump inhibitor (PPI) therapy is stopped [3]. 
Health-related quality of life (HRQOL) is increasingly being measured to assess the overall value of chronic therapies. The extent of impairment of HRQOL in patients with GERD has been evaluated using generic HRQOL questionnaires, GERD-specific quality of life (QOL) questionnaires, or a combination of the two types of instruments [1]. Such evaluations have found that the impact of GERD on HRQOL in affected individuals is proportional to the frequency and severity of heartburn, and is greater than that associated with many other chronic diseases [1]. QOL has become an important medical endpoint in clinical research [4], reflecting increasing awareness that traditional physiological endpoints often fail to correlate well with patients' functional status, general wellbeing, and satisfaction with therapy. Despite this, patient QOL data remain limited from studies of long-term GERD therapy, including treatment with histamine-2 receptor antagonists $\left(\mathrm{H}_{2} \mathrm{RAs}\right)$ and PPIs. In particular, no QOL data have yet been published on the treatment of GERD with PPIs for greater than 12 months' duration.

The present study investigated QOL in subjects receiving randomized, double-blind maintenance treatment with lansoprazole or ranitidine for 12 months, followed by longterm (up to 82 months), open-label, symptom-based, dosetitrated lansoprazole therapy for the prevention of $\mathrm{EE}$ recurrence.

\section{Methods}

\section{Study Design}

The M94-140 study (sponsored by Takeda Global Research \& Development Center, Inc., Deerfield, IL, [TAP Pharmaceutical Products Inc. is now a part of Takeda Global Research \& Development Center, Inc.]) was a randomized, parallel-group, multicenter clinical trial conducted in patients with EE. The trial consisted of an 8-week openlabel lansoprazole acute healing period, a double-blind treatment period (lansoprazole vs. ranitidine for the maintenance of healing) of up to 12 months [5], and a titrated open-label maintenance treatment period of up to 82 months with lansoprazole (Fig. 1). This report describes QOL data from the randomized, double-blind maintenance phase of the study and the titrated open-label maintenance phase that began when the subject had a recurrence of EE or completed the double-blind treatment period, whichever occurred first [6].

\section{Inclusion/Exclusion Criteria}

Male or female subjects who were at least 18 years of age with endoscopically proven EE ( $\geq$ Grade 2 according to a modified Hetzel-Dent grading scale developed by a committee of consultant gastroenterologists, and defined as one or more erosions/ulcerations involving $<10$ to $>50 \%$ of the distal $5 \mathrm{~cm}$ of the esophagus [3]) without coexisting duodenal ulcer and/or gastric ulcer $\geq 3 \mathrm{~mm}$ in diameter were eligible for participation in the acute healing period of this study. Subjects who had esophagitis due to a coexisting systemic disease (e.g., scleroderma, viral or fungal infection) or radiation, caustic or physiochemical trauma were not eligible to enter the study. To qualify for the doubleblind maintenance phase, subjects were to have endoscopically proven healed EE (Grade 0 or 1 ) at the end of the 8-week acute healing period, regardless of their symptom status. Thus, symptomatic subjects could be eligible for the double-blind maintenance phase. Subjects who completed the double-blind treatment period without relapse and those who experienced a recurrence of EE during double-blind treatment were eligible for inclusion in the titrated open-label treatment period.

Subjects were excluded if they required more than occasional use (occasional use defined as $\leq 10$ days per month) of non-steroidal anti-inflammatory drugs, including cyclooxygenase-2 inhibitors, during the study. However, aspirin $\leq 325 \mathrm{mg}$ /day for cardiovascular indications was acceptable. In addition, aluminum/magnesium hydroxide $\left(\right.$ Gelusil $\left.^{\circledR}\right)$ use was permitted for the relief of symptoms. All changes in concomitant medication (increased/ decreased dose or additional drugs) were recorded throughout the study. The use of anticoagulants, anti-ulcer/

Fig. 1 Study design

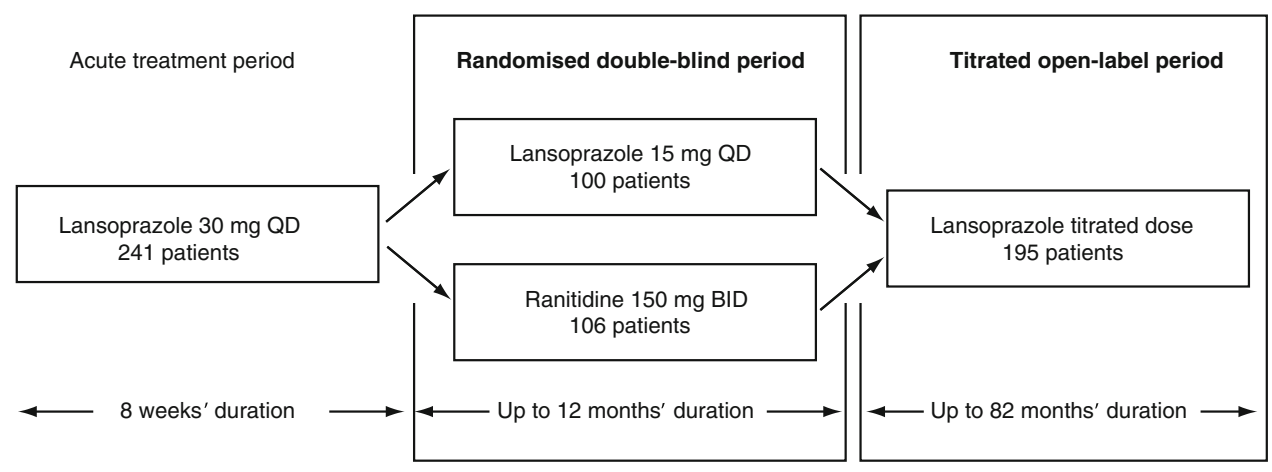


anti-reflux agents, or anticholinergics was not allowed. In addition, subjects were excluded if they required more than occasional use (occasional use defined as $\leq 10$ days per month) of corticosteroids equivalent to more than $10 \mathrm{mg}$ / day of prednisone. Full details of inclusion/exclusion criteria for entry into the initial acute treatment period have been previously described [5].

\section{Dosing and Duration of Treatment}

Subjects qualifying for the double-blind maintenance phase were randomized in an equal ratio to oral lansoprazole $15 \mathrm{mg}$ once daily or oral ranitidine $150 \mathrm{mg}$ twice daily, for up to 12 months. These doses are currently approved by the Food and Drug Administration (FDA) for the maintenance of healing of EE. For the open-label maintenance phase, healed subjects began treatment with lansoprazole $15 \mathrm{mg}$ once daily, while subjects who entered this phase unhealed received lansoprazole $30 \mathrm{mg}$ once daily until healing was documented. Once endoscopically documented healing had occurred, the dose of lansoprazole was reduced to $15 \mathrm{mg}$ once daily. During the remainder of the titrated open-label treatment period, the dose of lansoprazole was titrated as required (based on the recurrence of $\mathrm{EE}$ and/or symptomatic recurrence), with subjects receiving the minimum dose required to control their gastroesophageal reflux (ranging from a minimum dose of $15 \mathrm{mg} /$ day up to a maximum dose of $120 \mathrm{mg} /$ day) for up to 82 months.

\section{Efficacy Measurement}

Efficacy parameters were measured throughout the two maintenance phases (double-blind and titrated, open-label treatment) of the study. Protocol-required visits took place at months 1, 3, 6, 9, and 12 during the double-blind maintenance phase and every 12 months during the openlabel maintenance phase. Endoscopic examinations were undertaken at each scheduled visit (or if the subject was symptomatic) to document the presence or absence of $\mathrm{EE}$, thus allowing the recurrence of $\mathrm{EE}$ (primary clinical endpoint) to be monitored. For subjects with recurrence of $\mathrm{EE}$ at double-blind or open-label baseline, an evaluation of healing visit, including endoscopy, took place 8 weeks after the initiation of healing treatment (lansoprazole $30 \mathrm{mg} /$ day) and after any subsequent periods of healing treatment until healing was achieved. An unscheduled visit was also deemed to have taken place when a subject presented at the clinic for any reason at a time other than that regularly scheduled. At each visit, symptoms were also assessed through investigator interview, as were the number of Gelusil ${ }^{\circledR}$ tablets taken since the previous visit and subject QOL (see below).
QOL Assessment

QOL questionnaires were completed during both the double-blind and open-label study phases to evaluate the effect of disease status on subjects' physical, psychological, and social function. The questionnaires were developed using validated scales wherever possible, as described below. The questionnaires were self-administered by subjects at each protocol-required visit (see above) before all other visit procedures. QOL assessment was performed by evaluating the mean changes from baseline to subsequent visits for each item and/or scale score during each phase of the study.

General QOL scales used included scales from the RAND Corporation Medical Outcomes Study (MOS) questionnaire [7], the 36-item short form (SF-36) [8-10], and the General Well-Being Schedule [11]. All questionnaire items related to patient experience during the 4-week period prior to each scheduled visit, except for the general health perception scale of the SF-36 [8-10]; no time frame was specified for this scale. Where no validated scale was available, disease-specific scales were developed de novo by the Technology Assessment Group (San Francisco, CA) for Takeda Global Research and Development Center, Inc. A summary of the questionnaire scales is shown in Appendix 1.

\section{Safety}

The safety of lansoprazole was monitored through the assessment of adverse events, concurrent medication, and vital signs [6].

\section{Statistical Analyses for QOL Measurements}

All subjects who received at least one dose of lansoprazole or ranitidine during the double-blind maintenance phase of the study and at least one dose of lansoprazole during the titrated open-label maintenance phase were included in the QOL analyses for the respective period.

The QOL outcomes were the reported values for the parameters shown in Table 1. Whenever necessary, item scoring was reversed so that a higher score represented better health or a more positive outcome. Scale scores were calculated as the mean of the non-missing items comprising the scale. For scales consisting of only two items, a scale score was computed for a subject only if scores were present for both items. For scales consisting of more than two items, a scale score was computed for a subject only if scores were present for at least half of the items. All scores were transformed to a 0 to 100-point scale to facilitate comparison of results among scales (higher numbers indicating improvement/better outcome). The formula for 
Table 1 Primary quality of life outcomes

\begin{tabular}{|c|c|}
\hline Scale scores (comprised of multiple items) & Item scores \\
\hline General health perception & Comparative health \\
\hline General well-being & Health distress \\
\hline Energy and vitality & $\begin{array}{l}\text { Frequency of heartburn } \\
\text { symptoms }\end{array}$ \\
\hline Mental health & $\begin{array}{l}\text { Severity of heartburn } \\
\text { pain }\end{array}$ \\
\hline Sleep & $\begin{array}{l}\text { Comparative heartburn } \\
\text { bothersomeness }\end{array}$ \\
\hline Social functioning & $\begin{array}{l}\text { Degree of heartburn } \\
\text { bothersomeness }\end{array}$ \\
\hline Activity limitation problems & $\begin{array}{l}\text { Problems with taking } \\
\text { care of heartburn }\end{array}$ \\
\hline Eating and drinking problems & $\begin{array}{l}\text { Problems with living } \\
\text { normal life }\end{array}$ \\
\hline \multicolumn{2}{|l|}{ Symptom problems } \\
\hline \multicolumn{2}{|l|}{ Satisfaction with treatment } \\
\hline \multicolumn{2}{|l|}{ Indices } \\
\hline $\begin{array}{l}\text { Symptom index (symptom } \\
\text { frequency } \times \text { symptom bothersomeness) }\end{array}$ & \\
\hline
\end{tabular}

transformation differed for each scale, depending on the range of possible values, and was determined during the validation process.

The results are presented as baseline mean $( \pm \mathrm{SD})$ and mean change $( \pm \mathrm{SD})$ at each visit for each QOL item/scale score. For each study period, the baseline was the last available value on or before the first day of the period. Baseline values for the double-blind maintenance of healing period for both treatment groups are those reported at the end of the acute open-label healing phase prior to randomization, while baseline values for the open-label titration period are those reported after double-blind treatment with ranitidine or lansoprazole.

Changes from double-blind baseline in the mean item and scale scores at each scheduled visit were compared between lansoprazole and ranitidine using the CochranMantel-Haenszel test (for single items with ordered scores and scales with less than three items) or analysis of variance (ANOVA) (for scales with three or more items). Both analyses were adjusted for investigative center. Changes from titrated open-label baseline in the mean item and scale scores at each scheduled visit were analyzed using a paired $t$-test. Missing post-baseline item scores were imputed as the last observation carried forward (assuming no change from the previous visit regarding the specific item).

\section{Ethical Approval and Informed Consent}

All subjects were required to understand and sign the informed consent form prior to screening, and to understand and cooperate with the study procedures. Prior to initiating any study procedure, each investigator site was granted approval by an Institutional Review Board. The study adhered to the ethical principles stated in the Declaration of Helsinki (1996 revision) and was conducted in accordance with FDA guidelines, Guidelines for Good Clinical Practice governing clinical study conduct, and all applicable local regulations.

\section{Results}

\section{Subject Demographics}

A total of 206 subjects entered the double-blind maintenance phase of the study. Of these, 100 received lansoprazole $15 \mathrm{mg}$ once daily and 106 received ranitidine $150 \mathrm{mg}$ twice daily for up to 12 months or until recurrence of EE (Grade $\geq 2$ ). The demographic data for these subjects are summarized by treatment in Table 2. Overall, they had a mean age of 50.0 years (range: 19-82), and were mostly male $(67 \%, 139 / 206)$ and white $(90.0 \%, 185 / 206)$. Helicobacter pylori status at study enrollment was positive for $18 \%$ of subjects.

Most subjects $(95 \%, 195 / 206)$ completed the doubleblind treatment period (experienced recurrence or completed 12 months of therapy) and entered the dose-titrated open-label maintenance phase in accordance with the study criteria. The demographic summary data for these subjects were very similar to those for the 206 initial double-blind period enrollees: subjects were mostly male $(67 \%, 131 /$ $195)$ and white $(90 \%, 176 / 195)$, with a mean age of 50.8 years (range: $20-82$ ). Based on histological evaluation of gastric biopsies, $21 \%$ (40/195) of subjects were positive for $H$. pylori just prior to open-label treatment, and approximately half $(52 \%, 102 / 195)$ were experiencing recurrence of EE upon entry into the open-label period; of those subjects, 70 had received ranitidine and 32 had received lansoprazole during the double-blind maintenance phase [5].

During the titrated open-label treatment period, 105 of the 195 subjects withdrew from the trial. Reasons for premature discontinuation included adverse events (18 subjects, 9\%), personal issues (13 subjects, 7\%), poor compliance (nine subjects, 5\%), treatment with another drug that would interfere with the evaluation of the study drug (seven subjects, 4\%), pregnancy (two subjects, $1 \%$ ), therapeutic failure (one subject, $0.5 \%$ ), and closure of the study site or the subject was lost to follow-up (55 subjects, $28 \%)$.

All analyses were performed using all subjects with available data (intent-to-treat population). Although some subjects were treated for up to 82 months during the 
Table 2 Subject demographics at double-blind maintenance baseline

\begin{tabular}{ll}
$\begin{array}{l}\text { Lansoprazole } 15 \mathrm{mg} \\
\text { once daily } \\
(n=100)\end{array}$ & $\begin{array}{l}\text { Ranitidine } 150 \mathrm{mg} \\
\text { twice daily } \\
(n=106)\end{array}$ \\
\hline
\end{tabular}

\begin{tabular}{|c|c|c|}
\hline \multicolumn{3}{|l|}{ Gender, $n(\%)$} \\
\hline Male & $72(72)$ & $67(63)$ \\
\hline \multicolumn{3}{|l|}{ Race, $n(\%)$} \\
\hline White & $91(91)$ & $94(89)$ \\
\hline Black & $7(7)$ & $7(7)$ \\
\hline Other & $2(2)$ & $5(5)$ \\
\hline \multicolumn{3}{|l|}{ Age, years ${ }^{\mathrm{a}}$} \\
\hline Mean (SD) & $49.6(13.4)$ & $50.3(14.3)$ \\
\hline Range & $19-77$ & $19-82$ \\
\hline \multicolumn{3}{|c|}{ Erosive esophagitis grade, $n(\%)^{\mathrm{a}}$} \\
\hline Grade 2 & $58(58)$ & $63(59)$ \\
\hline Grade 3 & $36(36)$ & $32(30)$ \\
\hline Grade 4 & $6(6)$ & $11(10)$ \\
\hline H. pylori status, $n(\%)^{\mathrm{b}}$ & $N=99$ & $N=105$ \\
\hline Negative & $82(83)$ & $86(82)$ \\
\hline \multicolumn{3}{|l|}{ Weight (males), pounds ${ }^{\mathrm{a}}$} \\
\hline Mean $( \pm \mathrm{SD})$ & $193.1(33.8)$ & $203.7(31.7)$ \\
\hline Minimum-maximum & $130-310$ & $134-273$ \\
\hline \multicolumn{3}{|c|}{ Weight (females), pounds ${ }^{\mathrm{a}}$} \\
\hline Mean $( \pm \mathrm{SD})$ & $172.6(29.5)$ & $176.2(33.2)$ \\
\hline Minimum-maximum & $125-246$ & $97-237$ \\
\hline \multicolumn{3}{|l|}{ Body mass index } \\
\hline Mean $( \pm \mathrm{SD})$ & $28.5(4.5)$ & $29.5(4.8)$ \\
\hline Minimum-maximum & $20-47$ & $17-41$ \\
\hline \multicolumn{3}{|l|}{ Alcohol use, $n(\%)$} \\
\hline Current drinker & $52(52)$ & $52(49)$ \\
\hline Non-drinker ${ }^{\mathrm{c}}$ & $48(48)$ & $54(51)$ \\
\hline \multicolumn{3}{|c|}{ Current tobacco use, $n(\%)$} \\
\hline Tobacco user & $28(28)$ & $22(21)$ \\
\hline Tobacco non-user ${ }^{\mathrm{d}}$ & $72(72)$ & $84(79)$ \\
\hline
\end{tabular}

$S D$ standard deviation

a At acute baseline. Baseline weight is missing for one male subject in the ranitidine group

b Assessed by histology (Warthin-Starry silver stain) at acute baseline; the results were not available for two patients

${ }^{c}$ Includes ex-drinkers

${ }^{d}$ Includes ex-tobacco users

titrated open-label lansoprazole period, QOL data summarized by time period are presented up to 72 months due to the paucity of data after this time.

\section{Lansoprazole Dosing}

During the double-blind maintenance phase, the mean duration $( \pm \mathrm{SD})$ of dosing was $237 \pm 143$ days (range: 25.0-387.0) for lansoprazole and $89 \pm 111$ days (range:
3.0-373.0) for ranitidine. This difference was statistically significant $(P<0.05)$. During the titrated open-label treatment period, the mean duration of lansoprazole dosing was $56 \pm 24$ months (range: $<1-82$ months). The majority of subjects $(62 \%, 120 / 195)$ received titrated open-label maintenance treatment for at least 5 years ( $>60$ months). A summary of the duration of lansoprazole exposure for all subjects during the titrated open-label treatment period is shown in Table 3.

\section{Treatment Efficacy and Safety}

As previously reported for the double-blind maintenance period of the study, $67 \%$ of lansoprazole-treated patients remained healed of EE at the end of the 12-month period compared with only $13 \%$ of ranitidine-treated subjects [5]. By the end of the titrated open-label treatment period, the majority of subjects $(75 \%)$ also remained healed. Most subjects assessed during the titrated open-label treatment period had no symptoms or only mild symptoms of daytime heartburn $(95 \%, 175 / 185)$ and night-time heartburn $(94 \%, 174 / 185)$ at their final visit. Overall, lansoprazole was well tolerated during both maintenance phases of the study, with no unexpected adverse events or laboratory or biopsy findings.

\section{QOL}

The mean QOL scores were comparable between treatment groups at the double-blind maintenance period baseline. During this phase of the study, compared to the ranitidine group, the lansoprazole group showed a consistent (months 3 through 12$)$ significantly $(P \leq 0.05)$ greater improvement in the symptom pain-related QOL scales measuring heartburn severity and frequency (Table 4; Fig. 2), in the heartburn bothersomeness scales, and in other symptomspecific scales (symptom index scale and symptom problem scale). Consistent with symptom improvement, scales reflecting more general symptom-related QOL aspects (eating and drinking problems, social functioning, and the health distress scale) also showed significantly $(P \leq 0.05)$ greater improvements in the lansoprazole group compared to the ranitidine group during months 3 through 12 (Table 4). For other more global scales (the comparative health and general health scales), significantly $(P \leq 0.05)$ greater improvements in scores with lansoprazole compared to ranitidine were found at some visits (Table 5). In addition, lansoprazole-treated patients were significantly more satisfied with treatment than ranitidine-treated patients (months 3, 9, and 12).

Baseline QOL scores and mean changes from baseline at 12-month intervals during the titrated open-label treatment period are summarized in Tables 6 and 7. Of the global 
Table 3 Duration and extent of lansoprazole exposure for all subjects during the titrated open-label period

\begin{tabular}{|c|c|c|c|c|c|c|}
\hline \multirow[t]{2}{*}{ Duration (months) } & \multirow{2}{*}{$\begin{array}{l}\text { All subjects } \\
(n=195) \\
n(\%)\end{array}$} & \multicolumn{5}{|c|}{ By daily dose of lansoprazole ${ }^{a}$} \\
\hline & & $\begin{array}{l}\leq 15 \mathrm{mg} \\
n\end{array}$ & $\begin{array}{l}>15-30 \mathrm{mg} \\
n\end{array}$ & $\begin{array}{l}>30-60 \mathrm{mg} \\
n\end{array}$ & $\begin{array}{l}>60-90 \mathrm{mg} \\
n\end{array}$ & $\begin{array}{l}>90-120 \mathrm{mg} \\
n\end{array}$ \\
\hline$\leq 12$ & $16(8.2)$ & 62 & 78 & 37 & 5 & 5 \\
\hline$>12-24$ & $15(7.7)$ & 21 & 20 & 7 & 1 & 0 \\
\hline$>24-36$ & $13(6.7)$ & 16 & 17 & 6 & 0 & 1 \\
\hline$>36-48$ & $10(5.1)$ & 14 & 15 & 4 & 0 & 0 \\
\hline$>48-60$ & $21(10.8)$ & 17 & 13 & 6 & 1 & 0 \\
\hline$>60-72$ & $57(29.2)$ & 25 & 19 & 2 & 0 & 0 \\
\hline Mean \pm SD & $56.1 \pm 24.13$ & - & - & - & - & - \\
\hline Range & $<1-82.4$ & & & & & \\
\hline
\end{tabular}

SD standard deviation

${ }^{a}$ Subjects may have increased and/or decreased their dose during the study. Such subjects are counted once at each dose level administered; hence, the sum of subjects across doses is different from the total number of subjects enrolled in the titrated open-label treatment period

health scales, general health perception, comparative health, and health distress consistently demonstrated statistically significant improvements from baseline at 12 months, which were sustained during 72 months of follow-up (Table 6). In addition, a significant improvement compared to baseline was reported in 'Energy and vitality' at 12 months and in 'General well-being' at 48 months. All GERD-specific scales (social functioning, heartburn pain frequency, heartburn pain severity, comparative heartburn bothersomeness, degree of heartburn bothersomeness, symptom index, activity limitation, eating and drinking problems, symptom problems, taking care of heartburn problems, living normal life problems, and satisfaction with treatment) except sleep improved significantly $(P<0.001)$ at 12 months from titrated open-label baseline. The improvements were sustained throughout the 72month follow-up period (Table 7). The improvement in severity and frequency of heartburn observed during the double-blind maintenance period was also sustained throughout the 72-month period of open-label follow-up.

\section{Discussion}

The increasing interest in measuring subjects' QOL as an outcome reflects increasing awareness that traditional physiological endpoints often do not correlate well with patients' functional status, general well-being, and satisfaction with therapy. Improved QOL during the short-term treatment of GERD has been reported with ranitidine [12-14] and with PPIs [15-19]. Bytzer et al. [17] demonstrated that GERD patients treated with rabeprazole $20 \mathrm{mg}$ or omeprazole $20 \mathrm{mg}$ for 7 days showed improvement in QOL parameters with no significant differences between the two PPIs. Similarly, 4 weeks of treatment of GERD with esomeprazole $40 \mathrm{mg}$ produced significant and clinically meaningful improvements in QOL that were maintained during 6 months of maintenance therapy with esomeprazole [18]. However, few studies have assessed longer term GERD symptom prevention and QOL data in subjects receiving long-term PPIs.

The present study demonstrates that maintenance treatment with lansoprazole for 12 months is significantly better than maintenance treatment with ranitidine in improving subjects' QOL. Another study has also shown greater improvement in QOL with PPIs than with $\mathrm{H}_{2} \mathrm{RAs}$ during up to 6 months of maintenance treatment [20]. However, one study found no difference between PPIs and $\mathrm{H}_{2} \mathrm{RAs}$ in terms of the improvement in QOL during maintenance therapy [21]. All of these studies, however, showed that continued treatment of GERD is associated with improved QOL.

The results of the present study also show that longterm, dose-titrated, open-label use of lansoprazole in subjects with healed EE provides a continued and sustained improvement in physical, psychological, and social functioning (QOL measures). Such improvements in QOL are consistent with the decrease in severity and frequency of heartburn pain reported during the open-label period of this study and lend support to the efficacy data from this phase of the trial, which show that long-term continuous lansoprazole therapy is effective in maintaining remission of EE for up to 72 months, with relatively few subjects experiencing recurrence during this period [6]. In addition, the results of the current study show that, if symptoms develop (that could adversely affect QOL), symptom-based dose adjustment of lansoprazole is effective in controlling these symptoms [6].

In the present study, sleep improved during double-blind maintenance therapy with lansoprazole. The greatest 


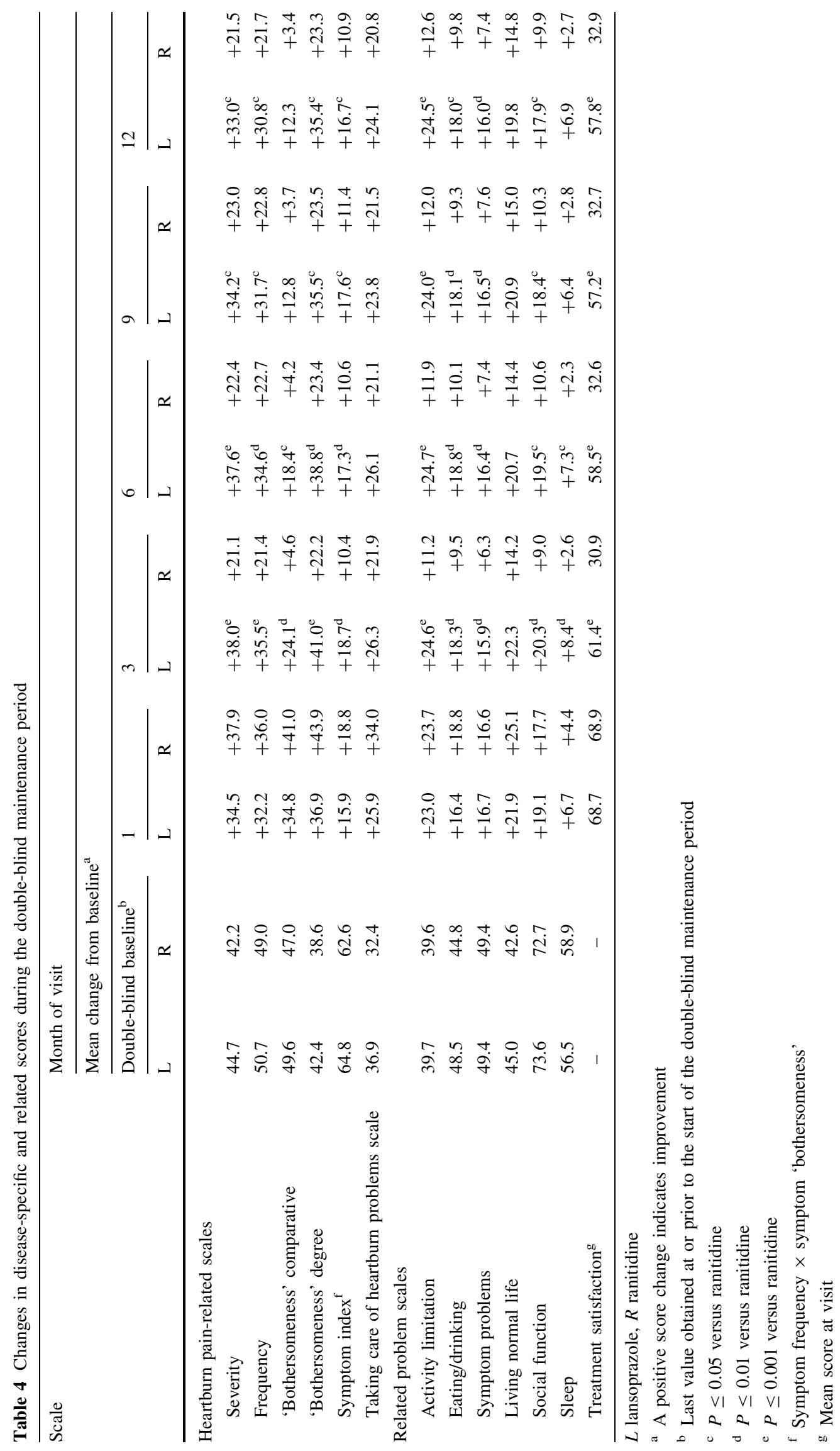


Fig. 2 Change in severity and frequency of heartburn during the double-blind maintenance period. A positive change indicates improvement

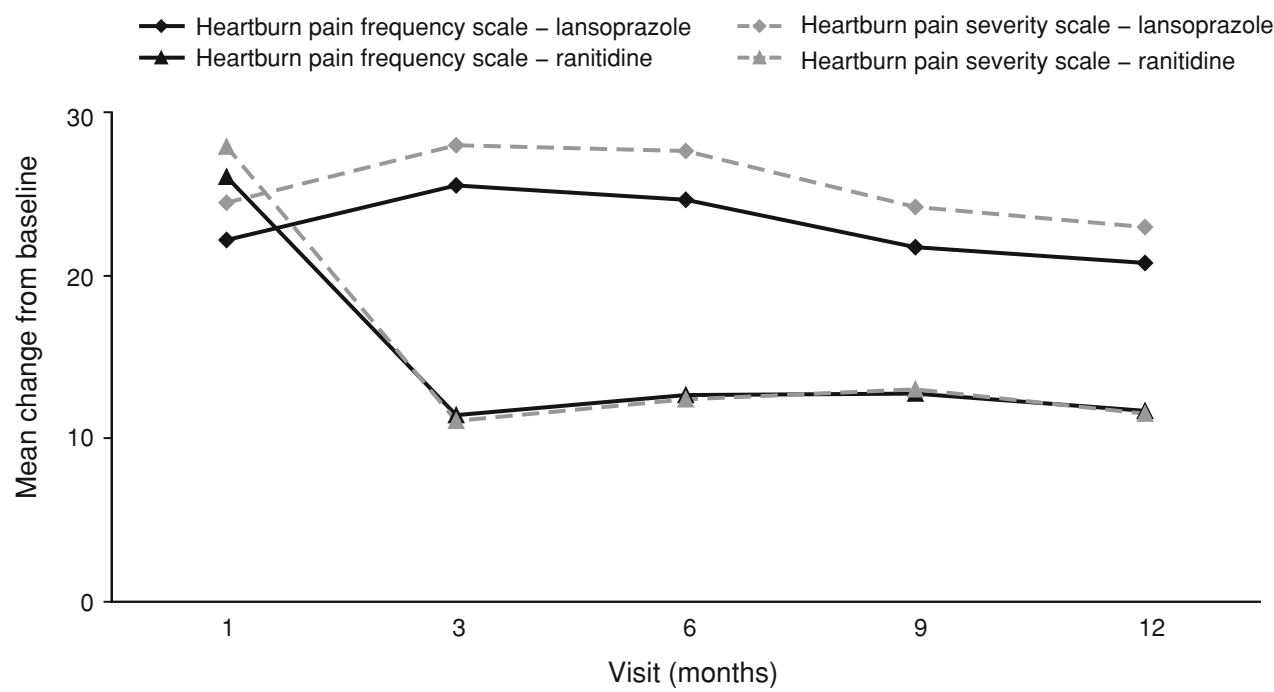

Table 5 Changes in global health scores during the double-blind maintenance period

\begin{tabular}{|c|c|c|c|c|c|c|c|c|c|c|c|c|}
\hline \multirow[t]{4}{*}{ Scale } & \multicolumn{12}{|c|}{ Month of visit } \\
\hline & \multicolumn{12}{|c|}{ Mean change from baseline ${ }^{a}$} \\
\hline & \multicolumn{2}{|c|}{ Double-blind baseline $^{\mathrm{b}}$} & \multicolumn{2}{|l|}{1} & \multicolumn{2}{|l|}{3} & \multicolumn{2}{|l|}{6} & \multicolumn{2}{|l|}{9} & \multicolumn{2}{|l|}{12} \\
\hline & $\mathrm{L}$ & $\mathrm{R}$ & $\mathrm{L}$ & $\mathrm{R}$ & $\mathrm{L}$ & $\mathrm{R}$ & $\mathrm{L}$ & $\mathrm{R}$ & $\mathrm{L}$ & $\mathrm{R}$ & $\mathrm{L}$ & $\mathrm{R}$ \\
\hline General health perception & 57.5 & 56.9 & $-0.4^{\mathrm{c}}$ & -5.4 & -0.4 & -4.3 & -1.7 & -4.3 & -1.2 & -4.8 & -3.0 & -4.4 \\
\hline Comparative health & 54.7 & 53.6 & +15.2 & +18.4 & $+7.0^{\mathrm{c}}$ & -2.3 & +2.1 & -2.8 & +0.5 & -2.8 & -1.0 & -3.6 \\
\hline Health distress & 43.4 & 47.6 & +15.5 & +15.1 & $+20.2^{\mathrm{d}}$ & +8.0 & $+18.3^{\mathrm{c}}$ & +9.2 & +17.3 & +10.4 & $+19.9^{\mathrm{c}}$ & +8.8 \\
\hline General well-being & 67.6 & 68.9 & -0.9 & -5.6 & -1.0 & -4.8 & -1.4 & -4.3 & -0.8 & -4.8 & -1.2 & -5.4 \\
\hline Energy and vitality & 45.5 & 45.0 & +0.6 & -2.9 & +1.3 & -1.4 & -0.8 & -1.9 & 0 & -2.8 & -1.3 & -3.5 \\
\hline Mental health & 62.1 & 63.4 & +2.4 & +1.7 & +4.3 & +2.2 & +3.8 & +2.2 & +4.9 & +2.5 & +5.0 & +2.0 \\
\hline
\end{tabular}

$L$ lansoprazole, $R$ ranitidine

a A positive score change indicates improvement

${ }^{\mathrm{b}}$ Last value obtained at or prior to the start of the double-blind maintenance period

c $P \leq 0.05$ versus ranitidine

${ }^{\mathrm{d}} P \leq 0.01$ versus ranitidine

improvement was observed after 3 months of treatment, and, thereafter, leveled off slightly. The improvement with lansoprazole was significantly greater than that with ranitidine after 3 and 6 months of treatment. The improvement in sleep during the double-blind maintenance phase was maintained during titrated open-label treatment with lansoprazole. Studies have shown that short-term (4-8 weeks) treatment with a PPI improves sleep in patients with GERD $[15,18,20,22]$. In these studies, the beneficial effect of PPI therapy on sleep leveled off after 2-4 weeks and then remained constant $[18,20,22]$, even during 6 months of maintenance therapy $[18,20]$. However, the results of the present study suggest that sleep improves during the early months of maintenance treatment with lansoprazole, and that this improvement is maintained during long-term treatment. Improvements in sleep have been shown to correlate with a reduction in the frequency and severity of heartburn episodes [15]. As GERD and its associated symptoms have a significant impact on subjects' QOL, successful therapeutic intervention is expected to be associated with a clinically significant improvement in HRQOL [1, 4, 23]. Indeed, the present data support previous studies in which acid suppression therapy improves HRQOL [22, 23]. For example, Mathias et al. [22] demonstrated that lansoprazole $15 \mathrm{mg}$ daily, lansoprazole $30 \mathrm{mg}$ daily, or omeprazole $20 \mathrm{mg}$ daily for 8 weeks significantly improved most HRQOL scales compared with placebo in a large group of patients with acute EE. The improvements in QOL leveled off after 2 weeks and were maintained in all of the study groups.

In the present study, improvements in QOL were observed after only 1 month of double-blind maintenance 
Table 6 Changes in global health scores during the titrated open-label period

\begin{tabular}{|c|c|c|c|c|c|c|c|}
\hline \multirow[t]{3}{*}{ Scale } & \multirow{3}{*}{ Open-label baseline $^{\mathrm{a}}$} & \multicolumn{6}{|c|}{ Month of visit } \\
\hline & & \multicolumn{6}{|c|}{ Mean change from baseline ${ }^{b}$} \\
\hline & & 12 & 24 & 36 & 48 & 60 & 72 \\
\hline General health perception & 64.2 & $+4.2^{\mathrm{d}}$ & $+5.4^{\mathrm{e}}$ & $+4.2^{\mathrm{d}}$ & $+5.1^{\mathrm{e}}$ & $+3.3^{\mathrm{c}}$ & $+3.5^{\mathrm{c}}$ \\
\hline Comparative health & 48.6 & $+7.9^{\mathrm{e}}$ & $+7.4^{\mathrm{e}}$ & $+5.0^{\mathrm{d}}$ & $+3.7^{\mathrm{c}}$ & $+5.8^{\mathrm{e}}$ & $+4.1^{\mathrm{c}}$ \\
\hline Health distress & 61.7 & $+5.1^{\mathrm{c}}$ & $+6.3^{\mathrm{d}}$ & $+6.5^{\mathrm{e}}$ & $+7.2^{\mathrm{e}}$ & +3.9 & $+6.2^{\mathrm{d}}$ \\
\hline General well-being & 66.3 & +2.4 & +2.7 & +1.8 & $+3.6^{\mathrm{c}}$ & +1.4 & +1.8 \\
\hline Energy and vitality & 55.3 & $+3.2^{\mathrm{c}}$ & +1.0 & +2.4 & +1.0 & +0.4 & +2.2 \\
\hline Mental health & 73.7 & +0.9 & +0.9 & +1.3 & +1.5 & +1.7 & +0.8 \\
\hline
\end{tabular}

${ }^{a}$ Last value obtained at or prior to the start of the titrated open-label period

b A positive score change indicates improvement

${ }^{c} P \leq 0.05$ versus baseline

${ }^{\mathrm{d}} P \leq 0.01$ versus baseline

e $P \leq 0.001$ versus baseline

Table 7 Changes in disease-specific scores during the titrated open-label period

\begin{tabular}{|c|c|c|c|c|c|c|c|}
\hline \multirow[t]{3}{*}{ Scale } & \multirow[t]{3}{*}{ Open-label baseline $^{\mathrm{a}}$} & \multicolumn{6}{|c|}{ Month of visit } \\
\hline & & \multicolumn{6}{|c|}{ Mean change from baseline ${ }^{\mathrm{b}}$} \\
\hline & & 12 & 24 & 36 & 48 & 60 & 72 \\
\hline \multicolumn{8}{|l|}{ Heartburn pain-related scales } \\
\hline Severity ${ }^{\mathrm{c}}$ & 68.0 & +17.1 & +16.8 & +17.7 & +18.4 & +18.4 & +19.3 \\
\hline Frequency $^{\mathrm{c}}$ & 73.0 & +14.8 & +13.8 & +15.2 & +16.1 & +15.6 & +15.6 \\
\hline 'Bothersomeness' comparative ${ }^{c}$ & 47.9 & +17.8 & +15.9 & +12.6 & +12.9 & +11.4 & +11.0 \\
\hline 'Bothersomeness' degree ${ }^{c}$ & 64.4 & +19.2 & +19.5 & +19.8 & +21.3 & +19.6 & +20.8 \\
\hline Symptom index ${ }^{\mathrm{c}, \mathrm{d}}$ & 77.4 & +7.5 & +7.6 & +7.7 & +8.2 & +7.8 & +7.9 \\
\hline Taking care of heartburn problems scale ${ }^{c}$ & 80.1 & +13.1 & +11.4 & +11.9 & +13.1 & +12.2 & +12.3 \\
\hline \multicolumn{8}{|l|}{ Related problems scales } \\
\hline Activity limitation ${ }^{c}$ & 79.6 & +9.6 & +9.7 & +9.9 & +10.5 & +9.2 & +10.1 \\
\hline Eating/drinking $^{\mathrm{c}}$ & 84.2 & +8.6 & +8.6 & +8.1 & +8.9 & +7.9 & +8.5 \\
\hline Symptom problems ${ }^{\mathrm{c}}$ & 84.1 & +9.0 & +8.4 & +8.7 & +9.7 & +8.6 & +9.3 \\
\hline Living normal life ${ }^{c}$ & 84.4 & +7.8 & +7.9 & +8.6 & +9.2 & +8.7 & +9.0 \\
\hline Social function ${ }^{\mathrm{c}}$ & 86.7 & +8.3 & +8.7 & +9.1 & +10.0 & +8.7 & +9.6 \\
\hline Sleep & 67.7 & +1.7 & +0.4 & +0.9 & +0.2 & +0.3 & +0.4 \\
\hline Treatment satisfaction ${ }^{\mathrm{c}}$ & 66.7 & +24.8 & +25.0 & +25.4 & +25.7 & +25.4 & +25.6 \\
\hline
\end{tabular}

${ }^{a}$ Last value obtained at or prior to the start of the titrated open-label period

b A positive score change indicates improvement

c $P \leq 0.001$ for all time points versus baseline

' Symptom index $=$ symptom frequency $\times$ symptom 'bothersomeness'

treatment with lansoprazole. These improvements tended to peak after 3 months of treatment and, thereafter, were maintained during 12 months of double-blind treatment. By contrast, the improvements in QOL with ranitidine appeared to peak after 1 month (at which point they were similar in magnitude to the improvements with lansoprazole) and then tended to drop off to a level lower than that observed at 1 month and significantly lower than that observed with lansoprazole at the same time point. The improvements in QOL with lansoprazole during the double-blind maintenance phase were sustained during symptom-based, dose-titrated, open-label therapy for up to 72 months.

The long-term effects of other PPIs on HRQOL have been investigated in subjects with GERD, although studies are limited to 12 months' treatment duration. In one study, 
esomeprazole and ranitidine treatment strategies were compared [20]. Following a 4-week symptom-control phase (esomeprazole $40 \mathrm{mg}$ once daily), patients were randomized to 6 months of esomeprazole $20 \mathrm{mg}$ once daily continuously or on-demand, or ranitidine $150 \mathrm{mg}$ twice daily continuously. Esomeprazole $40 \mathrm{mg}$ once daily improved QOL during the symptom-control phase and at 6 months; both esomeprazole regimens were significantly more effective than ranitidine in improving QOL. However, continuous esomeprazole once daily was better than esomeprazole on-demand in maintaining QOL, and was associated with greater patient satisfaction.

Several limitations of the current study should be highlighted. The final phase of the study was open-label in design, offering no comparison with placebo or active treatment. In addition, study drug information was not collected in sufficient detail during the study to allow for a calculation of compliance. The interpretation of data may also be affected by various factors, including spontaneous remission of GERD and subjective interpretation of symptoms. However, the paucity of relevant literature prevents any discussion as to whether 'switching' to openlabel medication may have had an effect on the symptoms reported. Regarding QOL assessment, enrollment for this long-term study began in 1995, whereas validated specific QOL instruments only became generally available for use in GERD studies after 1997. Thus, where no validated QOL scales were available, disease-specific scales were developed de novo by the Technology Assessment Group. Although such scales might be less accurate than validated HRQOL questionnaires [24], disease-specific instruments are more appropriate and may avoid the sensitivity issues previously described with some QOL tools, particularly generic instruments [25]. An additional limitation of the present study is that the minimum clinically important difference (MCID) for the HRQOL measures used was not identified for the GERD population. Thus, the proportion of subjects in each treatment group whose scores improved at least as much as the MCID in the HRQOL measures could not be calculated.

Some clinicians may not always agree that chronic daily use of PPIs is an appropriate therapeutic intervention. However, the lifetime management goals of GERD are to control esophageal as well as extraesophageal symptoms, maintain a stable non-inflamed esophageal mucosa, and prevent complications [26]. The current long-term study has confirmed the clinical efficacy and tolerability of PPI therapy in individuals with EE [6]. Significant improvements in QOL can be achieved in this patient population with long-term symptom-driven PPI therapy, as described in the present study, and this is particularly important as the impact of GERD on HRQOL can be greater than that associated with many other chronic diseases [1]. Thus,
PPIs, including lansoprazole, represent the mainstay of treatment in the long-term medical management of GERD.

In summary, maintenance treatment with lansoprazole for 12 months produced significantly greater improvements in general health and QOL indicators in subjects with EE than maintenance treatment with ranitidine. These improvements in QOL were sustained during 72 months of open-label, dose-titrated, maintenance treatment with lansoprazole. Thus, PPI therapy based on symptom-driven dose titration provides a sustained improvement in QOL during the long-term treatment of GERD.

Acknowledgments The authors would like to thank the investigators for their participation in the study. We would also like to thank Rx Communications (UK) and Susan Chambers for their assistance in preparing the manuscript and Smita Kothari for her contribution in reviewing the manuscript. Smita Kothari was an employee of TAP Pharmaceutical Products Inc. (now a part of Takeda Pharmaceuticals North America, Inc., Deerfield, IL) at the time of manuscript preparation.

Disclosures This study (M94-140) was sponsored by Takeda Global Research \& Development Center, Inc., Deerfield, IL (TAP Pharmaceutical Products Inc. is now a part of Takeda Global Research \& Development Center, Inc., Deerfield, IL) and was previously presented at Digestive Disease Week 2006 (Kovacs). Dr. Kovacs confirms that he has no conflicts of interest or disclosures. Dr. Freston has served as a consultant for Takeda Global Research \& Development Center, Inc., Takeda Pharmaceuticals North America, Inc., GlaxoSmithKline, and EnteroMedics, Inc. Dr. Haber is a consultant for Takeda Global Research \& Development Center, Inc. Dr. Peura is a consultant for Takeda Global Research \& Development Center, Inc., and member of the speaker bureau for Takeda Pharmaceuticals North America, Inc. Ms. Hunt and Dr. Atkinson are employees of Takeda Global Research \& Development Center, Inc.

Open Access This article is distributed under the terms of the Creative Commons Attribution Noncommercial License which permits any noncommercial use, distribution, and reproduction in any medium, provided the original author(s) and source are credited.

\section{Appendix. 1: Summary of QOL Scales Used}

General Scales

\section{General Health Perception}

This five-item scale from the RAND Corporation MOS questionnaire [7] assesses general health status, with each item measured on a five-point scale.

\section{Comparative Health}

This single item from the SF-36 of the MOS questionnaire [8-10] asks how the patient's health is compared to 4 weeks ago, and is measured on a five-point scale. 


\section{Health Distress}

This single item assesses the degree of concern/worry with health on a scale ranging from 0 to 10 , and comes from the 18-item General Well-Being Schedule [11].

\section{General Well-Being}

This two-item scale, adapted from the General Well-Being Schedule [11], consists of a life satisfaction item and an item asking how frequently the patient is bothered by illness, bodily disorder, pains, or fears about health. Both items are measured on a five-point scale.

\section{Energy and Vitality}

This five-item scale from the MOS questionnaire [7] assesses levels of energy and fatigue. The items are measured on a six-point scale.

\section{Mental Health}

This five-item scale from the MOS questionnaire [7] assesses anxiety, depression, and positive affect. The items are measured on a six-point scale.

\section{Disease-Specific Scales}

These scales and items were developed by TAP.

\section{Sleep}

This eight-item scale assesses sleeping problems resulting from the patient's heartburn condition. The items are measured on a six-point scale.

\section{Social Functioning Scale}

This two-item scale assesses social functioning problems resulting from the patient's heartburn condition. The items are measured on a five-point scale.

\section{Heartburn Symptoms-Frequency}

This single item asks patients how many days they had heartburn symptoms in the past 4 weeks. The item is measured on a six-point scale.

\section{Heartburn Pain-Severity}

This single item asks how severe the pain resulting from the heartburn condition has been during the past 4 weeks, and is measured on a scale of $0-10$.

\section{Comparative Heartburn Bothersomeness}

This single item asks if the patient's heartburn condition is worse, about the same, or better compared to 4 weeks ago, and is measured on a five-point scale.

\section{Degree of Heartburn Bothersomeness}

This single item asks patients about the degree of bothersomeness of their heartburn condition and is measured on a ten-point scale.

\section{Symptom Index}

Symptom frequency $\times$ symptom bothersomeness.

\section{Problems-Activity Limitations}

This four-item scale assesses problems with activity limitation resulting from the patient's heartburn condition. The items are measured on a five-point scale.

\section{Problems_Eating and Drinking}

This six-item scale assesses problems with eating and drinking resulting from the patient's heartburn condition. The items are measured on a five-point scale.

Problems-Symptoms

This seven-item scale assesses problems with heartburn symptoms resulting from the patient's heartburn condition. The items are measured on a five-point scale.

\section{Problems-Taking Care of Heartburn}

This single-item scale assesses the problem of taking care of heartburn resulting from the patient's heartburn condition. The item is measured on a five-point scale.

\section{Problems-Living a Normal Life}

This single-item scale assesses the problem of living a normal life resulting from the patient's heartburn condition. The item is measured on a five-point scale.

\section{Satisfaction with Treatment}

Satisfaction items were not asked at screening. Three questions were asked (satisfaction with relief from heartburn symptoms, with the results of the treatment program, and with the study medication), with each item measured on a five-point scale at each evaluation. 


\section{References}

1. Shaw MJ, Crawley JA. Improving health-related quality of life in gastro-oesophageal reflux disease. Drugs. 2003;63:2307-2316. doi:10.2165/00003495-200363210-00003.

2. DeVault KR, Castell DO. American College of Gastroenterology. Updated guidelines for the diagnosis and treatment of gastroesophageal reflux disease. Am J Gastroenterol. 2005;100:190200. doi:10.1111/j.1572-0241.2005.41217.x.

3. Hetzel DJ, Dent J, Reed WD, et al. Healing and relapse of severe peptic esophagitis after treatment with omeprazole. Gastroenterology. 1988;95:903-912.

4. Kamolz T, Pointner R, Velanovich V. The impact of gastroesophageal reflux disease on quality of life. Surg Endosc. 2003;17:1193-1199. doi:10.1007/s00464-002-9229-4.

5. Peura DA, Freston JW, Haber MM, et al. Lansoprazole for longterm maintenance therapy of erosive esophagitis: double-blind comparison with ranitidine. Dig Dis Sci. 2009;54:955-963.

6. Kovacs TO, Freston JW, Haber MM, et al. Long-term efficacy of lansoprazole in preventing relapse of erosive reflux esophagitis. Dig Dis Sci. 2009 [Epub ahead of print].

7. Stewart AL, Ware JE Jr, eds. Measuring functioning and wellbeing. The Medical Outcomes Study approach. Durham, North Carolina: Duke University Press; 1992.

8. Brazier JE, Harper R, Jones NM, et al. Validating the SF-36 health survey questionnaire: new outcome measure for primary care. BMJ. 1992;305:160-164.

9. Ware JE Jr, Sherbourne CD. The MOS 36-item short-form health survey $\left(\mathrm{SF}-36^{\circledR}\right)$. I. Conceptual framework and item selection. Med Care. 1992;30:473-483. doi:10.1097/00005650-19920600000002.

10. McHorney CA, Ware JE Jr, Raczek AE. The MOS 36-item shortform health survey $\left(\mathrm{SF}-36^{\circledR}\right)$ : II. Psychometric and clinical tests of validity in measuring physical and mental health constructs. Med Care. 1993;31:247-263. doi:10.1097/00005650-19930300000006.

11. Fazio AF. A concurrent validational study of the NCHS General Well-Being Schedule. Vital Health Stat 2. 1977;(73):1-53.

12. Rush DR, Stelmach WJ, Young TL, et al. Clinical effectiveness and quality of life with ranitidine vs placebo in gastroesophageal reflux disease patients: a clinical experience network (CEN) study. J Fam Pract. 1995;41(2):126-136.

13. Stacey JH, Miocevich ML, Sacks GE. The effect of ranitidine (as effervescent tablets) on the quality of life of GORD patients. $\mathrm{Br} \mathrm{J}$ Clin Pract. 1996;50:190-194, 196.

14. Earnest D, Robinson M, Rodriguez-Stanley S, et al. Managing heartburn at the 'base' of the GERD 'iceberg': effervescent ranitidine $150 \mathrm{mg}$ b.d. provides faster and better heartburn relief than antacids. Aliment Pharmacol Ther. 2000;14:911-918. doi: 10.1046/j.1365-2036.2000.00785.x.

15. Revicki DA, Sorensen S, Maton PN, et al. Health-related quality of life outcomes of omeprazole versus ranitidine in poorly responsive symptomatic gastroesophageal reflux disease. Dig Dis. 1998;16:284-291. doi:10.1159/000016878.

16. Wiklund I, Bardhan KD, Müller-Lissner S, et al. Quality of life during acute and intermittent treatment of gastro-oesophageal reflux disease with omeprazole compared with ranitidine. Results from a multicentre clinical trial. The European Study Group. Ital J Gastroenterol Hepatol. 1998;30:19-27.

17. Bytzer P, Morocutti A, Kennerly P, et al; ROSE Trial Investigators. Effect of rabeprazole and omeprazole on the onset of gastro-oesophageal reflux disease symptom relief during the first seven days of treatment. Scand J Gastroenterol. 2006;41:11321140. doi:10.1080/00365520600615781.

18. Pace F, Negrini C, Wiklund I, et al. The Italian ONE Investigators Study Group. Quality of life in acute and maintenance treatment of non-erosive and mild erosive gastro-oesophageal reflux disease. Aliment Pharmacol Ther. 2005;22:349-356. doi: 10.1111/j.1365-2036.2005.02558.x.

19. Ciovica R, Gadenstätter M, Klingler A, et al. Quality of life in GERD patients: medical treatment versus antireflux surgery. $J$ Gastrointest Surg. 2006;10:934-939. doi:10.1016/j.gassur.2006. 04.001.

20. Hansen AN, Bergheim R, Fagertun H, et al. Long-term management of patients with symptoms of gastro-oesophageal reflux disease-a Norwegian randomised prospective study comparing the effects of esomeprazole and ranitidine treatment strategies on health-related quality of life in a general practitioners setting. Int J Clin Pract. 2006;60:15-22. doi:10.1111/j.1368-5031.2006. 00768.x.

21. Kaplan-Machlis B, Spiegler GE, Zodet MW, et al. Effectiveness and costs of omeprazole vs ranitidine for treatment of symptomatic gastroesophageal reflux disease in primary care clinics in West Virginia. Arch Fam Med. 2000;9:624-630. doi:10.1001/ archfami.9.7.624.

22. Mathias SD, Castell DO, Elkin EP, et al. Health-related quality of life of patients with acute erosive reflux esophagitis. Dig Dis Sci. 1996;41:2123-2129. doi:10.1007/BF02071390.

23. Mathias SD, Colwell HH, Miller DP, et al. Health-related qualityof-life and quality-days incrementally gained in symptomatic nonerosive GERD patients treated with lansoprazole or ranitidine. Dig Dis Sci. 2001;46:2416-2423. doi:10.1023/A:1012363 501101.

24. Colwell HH, Mathias SD, Pasta DJ, et al. Development of a health-related quality-of-life questionnaire for individuals with gastroesophageal reflux disease: a validation study. Dig Dis Sci. 1999;44:1376-1383. doi:10.1023/A:1026647701477.

25. Velanovich V. Quality of life and severity of symptoms in gastrooesophageal reflux disease: a clinical review. Eur J Surg. 2000;166:516-525. doi:10.1080/110241500750008565.

26. Metz DC. Managing gastroesophageal reflux disease for the lifetime of the patient: evaluating the long-term options. Am J Med. 2004;117(Suppl 5A):49S-55S. 